\title{
Produção de Amônia na Fermentação In Vitro de Rações com Levedura, Uréia ou Farelo de Algodão ${ }^{1}$
}

\author{
Alexandre Amstalden Moraes Sampaio ${ }^{2}$, Paulo de Figueiredo Vieira ${ }^{3}$, Rodolfo Marques de Brito ${ }^{4}$
}

\begin{abstract}
RESUMO - O objetivo deste experimento foi avaliar a liberação de nitrogênio amoniacal $\left(\mathrm{N}-\mathrm{NH}_{3}\right)$ in vitro proveniente de rações contendo levedura, uréia e farelo de algodão, usadas na alimentação de ruminantes. Os dados relativos ao $\mathrm{N}-\mathrm{NH}_{3}$ encontrado nas amostras obtidas durante a primeira hora de fermentação apresentaram diferenças entre as rações preparadas com farelo de algodão e levedura, quando comparadas à ração com uréia, com valores de 7,52; 8,66; e 29,84 mg de N-NH$/ 100 \mathrm{~mL}$ de fluido ruminal, respectivamente. A mesma tendência foi observada até as 12 horas de fermentação, com valores de 1,05; 1,57; e 8,57 mg N-NH $3 / 100$ mL de fluido, para as rações com farelo de algodão, levedura e uréia, respectivamente. A análise dos dados relativos às amostras com 12 horas de fermentação mostrou tendência de diminuição da concentração de $\mathrm{N}-\mathrm{NH}_{3}$, atingindo os menores valores neste tempo de incubação.
\end{abstract}

Palavras-chave: amônia, farelo de algodão, fermentação ruminal, fontes de proteína, levedura, uréia

\section{Ammonia Production from In Vitro Fermentation of Diets with Dry Yeast, Urea or Cottonseed Meal}

\begin{abstract}
The objective of this trial was to evaluate the in vitro ammonia $\left(\mathrm{N}_{-} \mathrm{NH}_{3}\right)$ production in fermentation of diets with different protein sources (dry yeast, urea and cottonseed meal) used for ruminants diets. The data relative to the $\mathrm{N}_{-} \mathrm{NH}_{3}$ production measured in the first hour of incubation, showed differences between diets with cottonseed meal and dry yeast, compared with diets with urea, with values of 7.52; 8.66; and $29.84 \mathrm{mg} \mathrm{N}-\mathrm{NH}_{3} / 100 \mathrm{~mL}$ of ruminal fluid, respectively. The same pattern was observed until 12 hours of fermentation, with values of $1.05 ; 1.57$; and $8.57 \mathrm{mg} \mathrm{N}-\mathrm{NH}_{3} / 100 \mathrm{~mL}$. The analysis of data related to the 12 hourly sample of fermentation showed the trend of decreasing $\mathrm{N}-\mathrm{NH}_{3} / 100 \mathrm{~mL}$ concentration of ruminal fluid, reaching the lower values on 12 hours of fermentation.
\end{abstract}

Key Words: ammonia, cottonseed meal, dry yeast, protein sources, ruminal fermentation, urea

\section{Introdução}

O ruminante é dotado de sistema digestivo peculiar que permite a digestão de alimentos fibrosos, transformando-os em princípios nutritivos úteis, a partir do mutualismo existente entre o animal e a microbiota ruminal. A degradação de carboidratos estruturais, a hidrogenação de lipídios poli-insaturados e a hidrólise de oligo e polipeptídeos são processos importantes que se inter-relacionam constantemente na cinética de síntese de massa microbiana no rúmen, possibilitando a conversão de celulose e hemicelulose em carne, leite, lã e/ou trabalho motor.

A digestão da celulose e hemicelulose é dependente do acoplamento de bactérias à superfície do alimento e fortemente influenciada pela disponibilidade de $\mathrm{N}-\mathrm{NH}_{3}$ no líquido ruminal, pois o conjunto de microrganismos que digerem carboidratos estruturais utiliza $\mathrm{N}-\mathrm{NH}_{3}$ como fonte exclusiva de nitrogênio (BALDWIN et al., 1994). A reserva de $\mathrm{N}-\mathrm{NH}_{3}$ ruminal é extremamente dinâmica e depende da degradação de compostos nitrogenados protéicos e não-protéicos e da reciclagem de uréia por intermédio da saliva do animal. É de interesse o conhecimento da produção de amônia proporcionada pela fermentação de determinadas dietas, a fim de se conhecerem as concentrações de $\mathrm{N}-\mathrm{NH}_{3}$ que podem promover ou inibir o crescimento das bactérias no rúmen (ORSKOV, 1982).

A concentração ótima de $\mathrm{N}-\mathrm{NH}_{3}$ ruminal ainda não está bem estabelecida, mas alguns autores citam o valor de $5 \mathrm{mg} \mathrm{N}-\mathrm{NH}_{3} / 100 \mathrm{~mL}$ líquido ruminal como a concentração ótima (SATTER e SLYTER, 1974). Contudo, a variedade de alimentos utilizados na ali-

\footnotetext{
${ }^{1}$ Parte da Tese apresentada pelo primeiro autor à FCAVJ/UNESP para obtenção do título de Doutor em Zootecnia. Trabalho de pesquisa financiado pelo CNPq.

2 Zootecnista, Prof. Adjunto do Depto de Zootecnia (DZ) - Fac. Ciências Agrárias e Veterinárias (FCAV)/Unesp, v.a. Prof. Paulo D. Castellane, Km 5, CEP 14870-000, Jaboticabal (SP). Bolsista do CNPq. E-mail: sampaio@fcav.unesp.br

3 Engenheiro-Agrônomo, Prof. Titular do DZ - FCAVJ/Unesp. E-mail: pfvieira@fcav.unesp.br

${ }^{4}$ Zootecnista. Doutorando em Produção Animal FCAVJ/UNESP. Bolsista FAPESP. E-mail: rmbrito@fcav.unesp.br
} 
mentação dos ruminantes domésticos provoca elevada variabilidade nas condições de liberação sincronizada de $\mathrm{N}$ e energia, o que pode limitar de forma severa a produção e síntese de proteína microbiana no sistema retículo-ruminal.

Assim, o objetivo deste trabalho foi quantificar a concentração de $\mathrm{N}-\mathrm{NH}_{3}$ produzido a partir da incubação in vitro de rações contendo três diferentes fontes de proteína: farelo de algodão, uréia e levedura.

\section{Material e Métodos}

Foram preparadas três rações com feno de capim-de-Rhodes (Chloris gayana, Kunth), milho moído, farelo de algodão, levedura de cana-de-açúcar, uréia, melaço e minerais, segundo os tratamentos, que se constituíram de rações cuja variação foi a fonte protéica ( $\mathrm{RA}=$ ração com farelo de algodão; $\mathrm{RL}=$ ração com levedura; $\mathrm{RU}=$ ração com uréia). $\mathrm{O}$ feno foi previamente moído em moinho munido de peneira com crivos de 1/4" e utilizado na proporção de $60 \%$ em relação ao concentrado. Foi adicionado à ração $1 \%$ de núcleo mineral. A proporção dos ingredientes e a composição químico-bromatológica das rações encontram-se na Tabela 1.

As três rações foram misturadas em partes iguais e fornecidas em duas refeições diárias, durante 21 dias, a um bovino da raça Gir, com $550 \mathrm{~kg}$ de peso vivo e provido de cânula ruminal permanente. As coletas de líquido ruminal $(700 \mathrm{~mL})$ foram realizadas no período da manhã, antes da primeira refeição. O fluido foi retirado manualmente e filtrado em pano com malha fina, colocado em garrafas térmicas com capacidade para 1 litro, previamente aquecidas com água a $40^{\circ} \mathrm{C}$, sendo o material conduzido imediatamente ao laboratório para preparação e montagem do sistema de incubação.

Após a coleta do fluido ruminal, procedeu-se à filtragem do material em lã de vidro e misturou-se a uma solução tampão (McDOUGALL, 1948), durante 10 minutos antes da inoculação. O inóculo constituiuse de uma mistura de fluido ruminal com a solução tampão, na relação 1:1 v/v. A composição da solução tampão foi: $\mathrm{NaHCO}_{3}, 9,80 \mathrm{~g} / \mathrm{L} ; \mathrm{Na}_{2} \mathrm{PO}_{4} \cdot 7 \mathrm{H}_{2} \mathrm{O}$,

Tabela 1 - Proporções dos ingredientes nas rações experimentais e teores de matéria seca (MS), proteína bruta (PB), extrato etéreo (EE) e energia bruta (EB) dos ingredientes utilizados

Table 1 - Proportion of ingredients in experimental diets and dry matter (DM), crude protein (CP), ethereal extract (EE) and gross energy (GE) contents of used ingredients

\begin{tabular}{|c|c|c|c|c|c|c|c|}
\hline \multirow[b]{2}{*}{$\begin{array}{l}\text { Ingrediente } \\
\text { Ingredient }\end{array}$} & \multicolumn{3}{|c|}{$\begin{array}{c}\text { Ração }^{1} \\
\text { Diet }\end{array}$} & \multirow[b]{2}{*}{$\begin{array}{l}\text { MS } \\
D M\end{array}$} & \multicolumn{2}{|c|}{$\begin{array}{l}\% \text { da } M S \\
\% \text { of } D M \\
\end{array}$} & \multirow{2}{*}{$\begin{array}{c}\mathrm{kcal} / \mathrm{kg} \mathrm{MS} \\
\mathrm{kcal} / \mathrm{kg} \quad \mathrm{DM} \\
\mathrm{EB} \\
G E\end{array}$} \\
\hline & RA & $\mathrm{RL}$ & $\mathrm{RU}$ & & $\begin{array}{l}\mathrm{PB} \\
C P\end{array}$ & $\begin{array}{l}\mathrm{EE} \\
E E\end{array}$ & \\
\hline $\begin{array}{l}\text { Feno de capim-de-Rhodes } \\
\text { Rhodes grass hay }\end{array}$ & 60,0 & 60,0 & 60,0 & 89,7 & 7,3 & 2,0 & 3659 \\
\hline $\begin{array}{l}\text { Milho moído } \\
\text { Corn ground }\end{array}$ & 21,0 & 21,0 & 24,7 & 88,0 & 9,3 & 4,3 & 3713 \\
\hline $\begin{array}{l}\text { Farelo de algodão } \\
\text { Cottonseed meal }\end{array}$ & 15,0 & - & - & 91,0 & 41,6 & 1,6 & 4065 \\
\hline $\begin{array}{l}\text { Levedura } \\
\text { Yeast }\end{array}$ & - & 15,0 & - & 90,7 & 30,7 & 1,1 & 4138 \\
\hline $\begin{array}{l}\text { Uréia } \\
\text { Urea }\end{array}$ & - & - & 1,3 & - & $282,0^{2}$ & - & - \\
\hline $\begin{array}{l}\text { Melaço } \\
\text { Molasses }\end{array}$ & 3,0 & 3,0 & 3,0 & 75,0 & 3,2 & 0,1 & 4230 \\
\hline $\begin{array}{l}\text { Mistura mineral } \\
\text { Premix mineral }\end{array}$ & 1,0 & 1,0 & 1,0 & & & & \\
\hline $\begin{array}{l}\text { Ração }{ }^{1} \\
\text { Diet }\end{array}$ & & & & & & & \\
\hline $\begin{array}{l}\text { RA } \\
\text { RL } \\
\text { RU }\end{array}$ & & & & & $\begin{array}{l}12,7 \\
11,0 \\
10,4\end{array}$ & & $\begin{array}{l}3711 \\
3722 \\
3239\end{array}$ \\
\hline
\end{tabular}

${ }^{1} \mathrm{RA}$ - ração com farelo de algodão, $\mathrm{RL}$ - ração com levedura, $\mathrm{RU}$ - ração com uréia.

$R A$ - diet with cottonseed meal, $R L$ - diet with yeast, $R U$ - diet with urea.

$2 \square$ - equivalente protéico.

$P E$ - proteic equivalent. 
7,42 g/L; KCl, 0,57 g/L; $\mathrm{NaCl}, 0,47 \mathrm{~g} / \mathrm{L} ; \mathrm{MgSP}_{4} \cdot \mathrm{H}_{2} \mathrm{O}$, $0,12 \mathrm{~g} / \mathrm{L}$; e água q.s.p., $1 \mathrm{~L}$. Uma solução de $\mathrm{CaCl}_{2}$ foi adicionada à solução tampão na quantidade de $1 \mathrm{~mL} / \mathrm{L}$. Utilizaram-se tubos de inoculação com capacidade para $80 \mathrm{~mL}$, nos quais se adicionaram $0,5 \mathrm{~g}$ de amostra e $50 \mathrm{~mL}$ de inóculo e se efetuou o borbulhamento do material com $\mathrm{CO}_{2}$ por alguns segundos, na vazão de 2,5 L gás/min. Os tubos foram fechados com rolha de borracha equipadas com válvula de Bunsen.

Durante 12 horas, e a cada hora decorrida do início da incubação, foram coletadas amostras de $10 \mathrm{~mL}$ do conteúdo de cada recipiente e recolhidas em tubos de centrífuga contendo $1 \mathrm{~mL}$ de $\mathrm{HgCl}_{2} 5 \%$ $\mathrm{p} / \mathrm{v}$, com a finalidade de interromper o processo fermentativo e reduzir o $\mathrm{pH}$ do meio, a fim de se evitar a volatilização de $\mathrm{N}^{-\mathrm{NH}_{3}}$. Imediatamente após as coletas, as amostras foram centrifugadas a $3000 \mathrm{rpm}$ durante 15 minutos. Em seguida, procedeu-se à dosagem de amônia nas amostras, pela modificação da técnica de FENNER (1965). Foram tomados $2 \mathrm{~mL}$ de cada frasco e destilados em aparelho tipo micro-Kjedhal com adição de $5 \mathrm{~mL}$ de $\mathrm{KOH} 2 \mathrm{~N}$, sendo o aparelho regulado para destilar a um fluxo de $2 \mathrm{~mL} / \mathrm{min}$. $\mathrm{O}$ destilado foi recebido em $10 \mathrm{~mL}$ de $\mathrm{H}_{3} \mathrm{BO}_{3} 2 \%$ até um volume final de $50 \mathrm{~mL}$. O destilado foi então titulado com $\mathrm{HCl} 0,005 \mathrm{~N}(\mathrm{f}=0,9413)$, para se estimar a quantidade de $\mathrm{N}-\mathrm{NH}_{3}$ presente na amostra.

Os dados foram analisados segundo um delineamento inteiramente casualizado em esquema de parcelas subdivididas, constituindo-se os tratamentos principais nas fontes de proteína e os tratamentos secundários nos tempos de coleta, segundo o seguinte modelo (STEEL e TORRIE, 1981): $\mathrm{x}_{\mathrm{ijk}}=\mathrm{m}+\mathrm{a}_{\mathrm{i}}+\mathrm{d}_{\mathrm{ij}}+$ $\mathrm{b}_{\mathrm{k}}+(\mathrm{ab})_{\mathrm{ik}}+\mathrm{e}_{\mathrm{ijk}}$, em que $\mathrm{x}_{\mathrm{ijk}}$, valor observado na parcela; $\mathrm{m}$, média geral do tratamento; $\mathrm{a}_{\mathrm{i}}$, efeito da i-ésima ração $(\mathrm{i}=1,2,3) ; \mathrm{d}_{\mathrm{ij}}$, efeito do acaso na parcela com i-ésima ração e j-ésima $(j=1, \ldots, 4)$ repetição (erro a); $b_{k}$, efeito do tempo de coleta $(\mathrm{k}=1, \ldots, 12) ;(\mathrm{ab})_{\mathrm{ik}}$, efeito da interação entre i-ésima ração e do tempo de coleta $\mathrm{k}$; e $\mathrm{e}_{\mathrm{ijk}}$, efeito do acaso na subparcela com i-ésima ração, tempo de coleta k e j-ésima repetição (erro b).

\section{Resultados e Discussão}

Os valores médios de concentração de $\mathrm{N}-\mathrm{NH}_{3}$ no líquido ruminal foram máximos durante as duas primeiras horas e variaram de 7,52 a 29,84 mg/100 mL nas rações contendo farelo de algodão e uréia, respectivamente, ambas com 1 hora de fermentação. A ração contendo uréia apresentou valores superiores àquela com levedura e farelo de algodão, que, no entanto, não diferiram entre si. Os resultados encontram-se na Tabela 2. Comparativamente, os maiores valores de concentração de $\mathrm{N}-\mathrm{NH}_{3}$ em rações contendo uréia foram observados por RUMSEY (1978) e DAUGHERTY e CHURCH (1982), evidenciando a rápida hidrólise do $\mathrm{N}$ não-protéico, em razão da solubilização da uréia em meio aquoso (BRIGGS, 1977).

Alguns resultados de síntese de proteína microbiana, população de microrganismos no rúmen, retenção de $\mathrm{N}$ e ganho de peso por bovinos foram considerados satisfatórios com $5 \mathrm{mg} \mathrm{N}-\mathrm{NH}_{3} / 100 \mathrm{~mL}$ de líquido ruminal (SATTER e ROFFLER, 1975); $28 \mathrm{mg} / 100 \mathrm{~mL}$ (MILLER, 1973); e $51 \mathrm{mg} / 100 \mathrm{~mL}$ (DAVIDOVICH et al., 1977). Contudo, os trabalhos de SATTER e SLYTER (1974), realizados in vitro, mostraram que concentrações de $\mathrm{N}-\mathrm{NH}_{3}$ superiores a $5 \mathrm{mg} / 100 \mathrm{~mL}$ de fluido representaram excesso que não foi utilizado para a síntese microbiana. Em experimento conduzido por SLYTER et al. (1979), animais recebendo dieta com $11,1 \%$ de proteína bruta apresentaram concentração de $2,2 \mathrm{mg} \mathrm{N}-\mathrm{NH}_{3} / 100 \mathrm{~mL}$, enquanto os animais que receberam dietas com 13,3\% de proteína bruta revelaram acúmulo de $\mathrm{N}-\mathrm{NH}_{3}$ no rúmen, indicando que os microrganismos foram supridos com mais $\mathrm{N}-\mathrm{NH}_{3}$ do que poderiam utilizar.

Tabela 2 - Valores médios de $\mathrm{N}-\mathrm{NH}_{3}(\mathrm{mg} / 100 \mathrm{~mL}$ de líquido ruminal) produzido na fermentação in vitro das rações

Table 2 - Mean values of $\mathrm{N}-\mathrm{NH}_{3}$ ( $\mathrm{mg} / 100 \mathrm{~mL}$ of ruminal fluid), produced in the in vitro fermentation of diets

\begin{tabular}{|c|c|c|c|c|}
\hline \multirow{2}{*}{$\begin{array}{l}\text { Tempo de } \\
\text { incubação (h) } \\
\text { Incubation time }\end{array}$} & \multicolumn{4}{|c|}{$\begin{array}{c}\text { Ração }{ }^{1} \\
\text { Diet }\end{array}$} \\
\hline & RA & $\mathrm{RL}$ & $\mathrm{RU}$ & $\begin{array}{c}\text { Branco } \\
\text { White }\end{array}$ \\
\hline 1 & $7,52^{\mathrm{a}}$ & $8,66^{\mathrm{a}}$ & $29,84^{b}$ & $\overline{5,07^{c}}$ \\
\hline 2 & $8,31^{\mathrm{a}}$ & $8,86^{\mathrm{a}}$ & $29,05^{\mathrm{b}}$ & $6,82^{c}$ \\
\hline 3 & $4,55^{\mathrm{a}}$ & $7,52^{\mathrm{a}}$ & $28,61^{\mathrm{c}}$ & $7,09^{b}$ \\
\hline 4 & $6,30^{\mathrm{a}}$ & $7,09^{\mathrm{a}}$ & $26,95^{\mathrm{b}}$ & $7,52^{\mathrm{b}}$ \\
\hline 5 & $4,81^{\mathrm{a}}$ & $5,07^{\mathrm{a}}$ & $25,37^{b}$ & $8,05^{\mathrm{a}}$ \\
\hline 6 & $2,97^{\mathrm{a}}$ & $4,11^{\mathrm{a}}$ & $22,05^{b}$ & $7,96^{\mathrm{c}}$ \\
\hline 7 & $2,01^{\mathrm{a}}$ & $2,89^{\mathrm{a}}$ & $18,37^{\mathrm{b}}$ & $8,66^{\mathrm{c}}$ \\
\hline 8 & $1,40^{\mathrm{a}}$ & $1,84^{\mathrm{a}}$ & $15,14^{b}$ & $8,57^{\mathrm{c}}$ \\
\hline 9 & $1,40^{\mathrm{a}}$ & $1,84^{\mathrm{a}}$ & $13,56^{\mathrm{b}}$ & $8,92^{\mathrm{c}}$ \\
\hline 10 & $1,05^{\mathrm{a}}$ & $1,40^{\mathrm{a}}$ & $10,41^{b}$ & $8,57^{c}$ \\
\hline 11 & $1,14^{\mathrm{a}}$ & $1,31^{\mathrm{a}}$ & $9,27^{b}$ & $10,06^{\mathrm{b}}$ \\
\hline 12 & $1,05^{\mathrm{a}}$ & $1,57^{\mathrm{a}}$ & $8,57^{\mathrm{b}}$ & $10,57^{\mathrm{c}}$ \\
\hline \multicolumn{5}{|c|}{$\begin{array}{l}{ }^{1} \mathrm{RA} \text { - ração com farelo de algodão, } \mathrm{RL} \text { - ração com levedura, } \mathrm{RU} \text { - } \\
\text { ração com uréia. } \\
R A \text { - diet with cottonseed meal, } R L \text { - diet with yeast, } R U \text { - diet with urea. } \\
\text { Médias seguidas de letras iguais (nas linhas) não diferiram pelo } \\
\text { teste Tukey }(\mathrm{P}<0,05) \text {. } \\
\text { Means followed by same letters (in rows) did not differ by Tukey test }(P<.05) \text {. }\end{array}$} \\
\hline
\end{tabular}


No presente trabalho, os níveis de $\mathrm{N}-\mathrm{NH}_{3}$ detectados para as rações contendo farelo de algodão e levedura diminuíram com o decorrer das horas de fermentação, a partir dos valores máximos de $8,31 \mathrm{e}$ $8,86 \mathrm{mg} / 100 \mathrm{~mL}$, respectivamente, atingidos com 2 horas de fermentação. Estes valores estão abaixo dos relatados por MILLER (1973) como ideais para a atividade microbiana, de $28 \mathrm{mg} / 100 \mathrm{~mL}$. Apenas a ração com uréia apresentou variação de 29,84 a 28,61 mg N$\mathrm{NH}_{3} / 100 \mathrm{~mL}$ até a terceira hora de fermentação.

Pela Figura 1, observa-se que houve queda gradativa na concentração de amônia nas horas subseqüentes às duas horas iniciais para todos os tratamentos, exceto para o branco, que aumentou a concentração linearmente com os tempos de fermentação. Para o tratamento com uréia, essas diminuições foram mais acentuadas e para os outros, menos intensas, permanecendo praticamente constantes a partir de 8 horas de fermentação. Esta variação pode ser observada na Tabela 3, que mostra diferenças significativas para alguns dos valores obtidos durante os diferentes tempos de fermentação. As curvas de regressão que descrevem o comportamento da produção de $\mathrm{N}-\mathrm{NH}_{3}$ são apresentadas na Tabela 4. Os valores de $5 \mathrm{mg} \mathrm{N}-\mathrm{NH}_{3} / 100 \mathrm{~mL}$ são, então, obtidos com 3,92; 4,97; e 12,61 horas de fermentação, o que

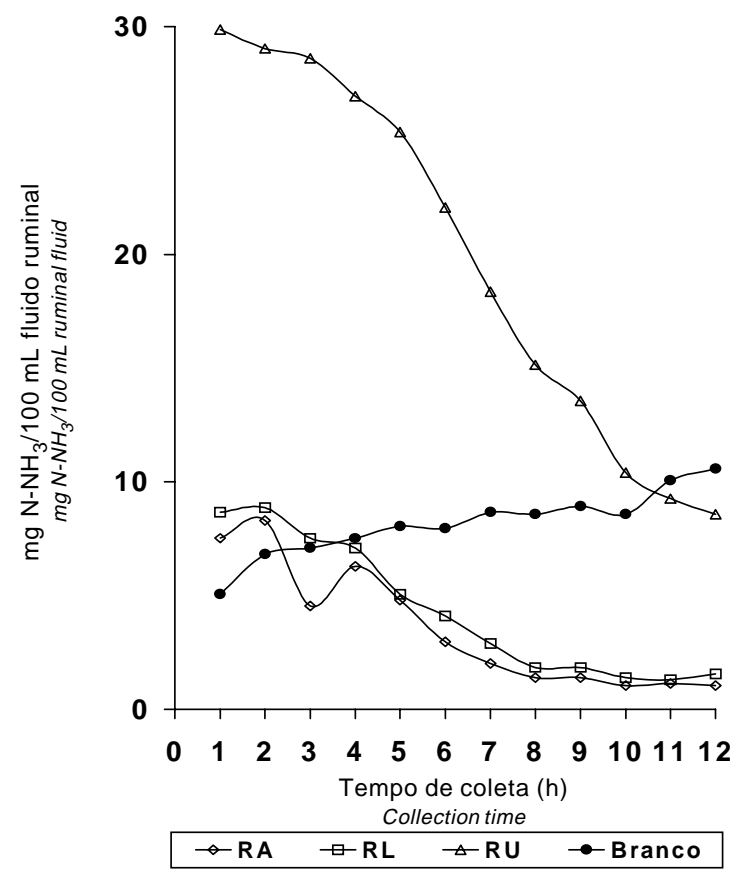

Figura 1 - Variação da concentração de $\mathrm{N}-\mathrm{NH}_{3}$ durante a fermentação de rações contendo diferentes fontes de proteína: farelo de algodão (RA), levedura $(R L)$ e uréia $(\mathrm{RU})$.

Figure 1 - Variation of $\mathrm{N}-\mathrm{NH}_{3}$ concentdiet during the fermentation of diets containing different protein sources: cottonseed meal $(R A)$, dry yeast $(R L)$ and urea $(R U)$.

Tabela 3 - Valores médios de $\mathrm{N}-\mathrm{NH}_{3}$ ( $\mathrm{mg} / 100 \mathrm{~mL}$ de líquido ruminal), produzidos na fermentação in vitro das rações, em cada tempo de fermentação

Table 3 - Mean values of $\mathrm{N}-\mathrm{NH}_{3}(\mathrm{mg} / 100 \mathrm{~mL}$ of ruminal fluid), produced in the in vitro fermentation of diets, in each fermentation time

\begin{tabular}{|c|c|c|c|c|c|c|c|}
\hline \multicolumn{6}{|c|}{$\begin{array}{c}\text { Ração }{ }^{1} \\
\text { Diet }\end{array}$} & & \\
\hline \multicolumn{2}{|c|}{ RA } & \multicolumn{2}{|c|}{ RL } & \multicolumn{2}{|c|}{ RU } & \multicolumn{2}{|c|}{ Branco (White) } \\
\hline $\begin{array}{l}\text { Tempo (h) } \\
\text { Time }\end{array}$ & $\overline{\mathrm{N}-\mathrm{NH}_{3}}$ & $\begin{array}{c}\text { Tempo (h) } \\
\text { Time }\end{array}$ & $\mathrm{N}-\mathrm{NH}_{3}$ & $\begin{array}{c}\text { Tempo }(\mathrm{h}) \\
\text { Time }\end{array}$ & $\mathrm{N}-\mathrm{NH}_{3}$ & $\begin{array}{c}\text { Tempo }(\mathrm{h}) \\
\text { Time }\end{array}$ & $\mathrm{N}-\mathrm{NH}_{3}$ \\
\hline 2 & $8,31^{\mathrm{a}}$ & 2 & $8,84^{\mathrm{a}}$ & 1 & $29,84^{\mathrm{a}}$ & 12 & $10,67^{\mathrm{a}}$ \\
\hline 1 & $7,52^{\mathrm{ab}}$ & 1 & $8,66^{\mathrm{a}}$ & 2 & $29,05^{\mathrm{a}}$ & 11 & $10,06^{\mathrm{ab}}$ \\
\hline 4 & $6,30^{\mathrm{bc}}$ & 3 & $7,52^{\mathrm{ab}}$ & 3 & $28,61^{\mathrm{a}}$ & 9 & $8,92^{\mathrm{bc}}$ \\
\hline 5 & $4,81^{\mathrm{cd}}$ & 4 & $7,09^{\mathrm{bc}}$ & 4 & $26,95^{\mathrm{b}}$ & 7 & $8,66^{\mathrm{bc}}$ \\
\hline 3 & $4,55^{\mathrm{d}}$ & 5 & $5,70^{c}$ & 5 & $25,37^{\mathrm{c}}$ & 8 & $8,57^{\mathrm{bcd}}$ \\
\hline 6 & $2,97^{\mathrm{e}}$ & 6 & $4,11^{\mathrm{d}}$ & 6 & $22,05^{\mathrm{d}}$ & 10 & $8,57^{\mathrm{bcd}}$ \\
\hline 7 & $2,01^{\mathrm{ef}}$ & 7 & $2,89^{\mathrm{de}}$ & 7 & $18,37^{\mathrm{e}}$ & 5 & $8,05^{\mathrm{cde}}$ \\
\hline 8 & $1,40^{\mathrm{f}}$ & 8 & $1,84^{\mathrm{ef}}$ & 8 & $15,14^{\mathrm{f}}$ & 6 & $7,96^{\text {cde }}$ \\
\hline 9 & $1,40^{\mathrm{f}}$ & 9 & $1,84^{\mathrm{ef}}$ & 9 & $13,56^{\mathrm{g}}$ & 4 & $7,52^{\text {cde }}$ \\
\hline 11 & $1,14^{\mathrm{f}}$ & 12 & $1,57^{\mathrm{ef}}$ & 10 & $10,41^{\mathrm{h}}$ & 3 & $7,09^{\mathrm{de}}$ \\
\hline 10 & $1,05^{\mathrm{f}}$ & 10 & $1,40^{\mathrm{ef}}$ & 11 & $9,27^{\mathrm{hi}}$ & 2 & $6,82^{\mathrm{e}}$ \\
\hline 12 & $1,05^{\mathrm{f}}$ & 11 & $1,31^{\mathrm{f}}$ & 12 & $8,57^{j}$ & 1 & $5,07^{\mathrm{f}}$ \\
\hline
\end{tabular}

${ }^{1} \mathrm{RA}$ - ração com farelo de algodão, $\mathrm{RL}$ - ração com levedura, $\mathrm{RU}$ - ração com uréia.

$R A$ - diet with cottonseed meal, $R L$ - diet with yeast, $R U$ - diet with urea.

Médias seguidas de letras iguais (nas colunas) não diferiram pelo teste Tukey $(P<0,05)$.

Means followed by same letters (in columns) did not differ by Tukey test $(P<.05)$. 
Tabela 4 - Regressão para concentração de $\mathrm{N}-\mathrm{NH}_{3}$ (mg/100 mL de líquido ruminal), em função do tempo de coleta $(\mathrm{y})$ para as rações com uréia, levedura e farelo de algodão

Table 4 - Regression for $\mathrm{N}-\mathrm{NH} 3$ ( $\mathrm{mg} / 100 \mathrm{~mL}$ of ruminal fluid), on the collection time $(y)$ for diets with urea, dry yeast and cottonseed meal

\begin{tabular}{lcc}
\hline $\begin{array}{l}\text { Ração } 1 \\
\text { Diets }\end{array}$ & $\begin{array}{c}\text { Equação } \\
\text { Equation }\end{array}$ & $\mathrm{R}^{2}$ \\
\hline RU & $\mathrm{y}=-0,047 \times 2-1,6994 \mathrm{x}+33,073$ & 0,97 \\
RL & $\mathrm{y}=0,0571 \mathrm{x} 2-1,5323 \mathrm{x}+11,214$ & 0,96 \\
RA & $\mathrm{y}=0,0569 \mathrm{x} 2-1,4249 \mathrm{x}+9,7211$ & 0,90 \\
\hline
\end{tabular}

1 RA - ração com farelo de algodão, RL - ração com levedura, RU ração com uréia

$R A$ - diet with cottonseed meal, RL - diet with yeast, $R U$ - diet with urea

indica a necessidade de o ajuste dietético prover aportes energéticos com liberação máxima nestes horários, em cada uma das dietas estudadas.

O rápido desaparecimento da amônia do rúmen pode ser atribuído parcialmente à sua absorção pela parede ruminal e/ou pela utilização pelos microrganismos ruminais (NOLAN et al., 1973). Nesse caso, é preciso haver fornecimento de energia suficiente para garantir máxima taxa de fermentação ruminal. No caso do branco, é preciso considerar que o aparecimento do $\mathrm{N}-\mathrm{NH}_{3}$ deve-se principalmente à degradação da proteína e do nitrogênio não-protéico residual contido no líquido ruminal coletado e/ou à degradação da própria proteína microbiana, ainda que ambas tenham ocorrido em pequena intensidade.

O tratamento com uréia teve sua maior degradação nas primeiras horas após o início de fermentação, devido à sua maior solubilidade. Nas horas seguintes, predominou a utilização do $\mathrm{N}-\mathrm{NH}_{3}$ do meio pelos microrganismos, fazendo com que houvesse diminuição acentuada em relação aos demais tratamentos. As concentrações de $\mathrm{N}-\mathrm{NH}_{3}$ nas dietas com farelo de algodão e levedura iniciaram-se em patamares mais baixos, o que leva a considerar que houve maior equilíbrio entre a degradação de carboidratos e a captação de $\mathrm{N}-\mathrm{NH}_{3}$ pelos microrganismos nas dietas integradas por estas duas fontes protéicas.

Pela Tabela 2, verifica-se que não houve diferenças para os tratamentos com farelo de algodão e levedura durante todo o período, exceto na terceira hora, na qual se observou brusca diminuição na concentração de $\mathrm{N}-\mathrm{NH}_{3}$ para o tratamento com farelo de algodão, o que pode estar associado às diferenças na solubilidade da proteína dessas duas fontes. Nos demais horários, o tratamento contendo levedura não foi diferente do tratamento com farelo de algodão, em contraste com os dados obtidos por MACHADO (1983), utilizando as mesmas fontes de proteína.

\section{Conclusões}

As rações cujas fontes protéicas foram o farelo de algodão e a levedura demonstraram semelhança quanto à liberação de $\mathrm{N}-\mathrm{NH}_{3}$ in vitro.

A ração com uréia apresentou concentrações de $\mathrm{N}-\mathrm{NH}_{3}$ sempre superiores às demais fontes protéicas, independentemente do tempo de fermentação.

\section{Referências Bibliográficas}

BALDWIN, R.L., CALVER, C.C., HANIGAN, M.D. et al 1994. Modelling amino acid metabolism in ruminants. In: D’MELLO, J.P.F. Amino acids in farm animal nutrition. Wallingford: Cab International.1.ed. p.281-306.

BRIGGS, M.H. 1977. Urea as a protein supplement. Londres:Pergamon Press. 466p.

DAUGHERTY, D.A., CHURCH, D.C. 1982. "In vivo" and "In vitro" evaluation of feather and hair meals in combination with urea for ruminants. J. Anim. Sci., 54:345.

DAVIDOVICH, A., BARTLEY, E.E., CHAPMAN, T.E. et al. 1977. Ammonia toxicity in cattle. II. Changes in corotid and jugular blood components associated with toxicity. J. Anim. Sci., 44(4):702-709.

FENNER, H. 1965. Methods for determining total volatile base in rumen fluid by steam distillation. J. Dairy. Sci., 48(3):249-251.

MACHADO, P.F. Valor nutritivo da levedura, resíduo da produção de álcool para vacas em lactação. São Paulo, SP. FCF/USP, 1983. Tese (Doutorado) - Universidade de São Paulo, 1983.

McDOUGALL, E.I. 1948. The composition and output of sheep's saliva. J. Biochem., 43:99.

MILLER, E.L. 1973. Symposium on nitrogen utilization by the ruminant. Evaluation of foods as sources of nitrogen and amino acids. Proc. Nutr. Soc., 32(2):79.

NOLAN, J.V., NORTON, B.W., LENG, R.A. 1973. Nitrogen cycling in sheep. Proc. Nutr. Soc., 32(2):93-98.

ORSKOV, E.R. 1982. Protein nutrition in ruminants. Londres: Academic Press. 160p.

RUMSEY, T.S. 1978. Ruminal fermentation products and plasma ammonia of fistulated steers fed apple-pomace-urea diets. J. Anim. Sci., 47(4):967-976.

SATTER, L.D., ROFFLER, H. 1975. Nitrogen requirement and utilization in dairy cattle. J. Dairy Sci., 58(8):1219-1237.

SATTER, L.D., SLYTER, L.L. 1974. Effect of ammonia concentdiet on ruminal microbial protein production "in vitro". Brit. J. Nutr., 32(2):199-208.

SLYTER, L.L, SATTER, L.D., DINIUS, D.A. 1979. Effect of ruminal ammonia concentdiet on nitrogen utilization by steers. J. Anim. Sci., 48(4):906-912.

STEEL, R.G.D., TORRIE, J.H. 1981. Principles and procedures of statistics. A biometrial approach. 2.ed., Nova York: Mc Graw-Hill. 633p.

Recebido em: 12/05/99 Aceito em: 30/08/99 